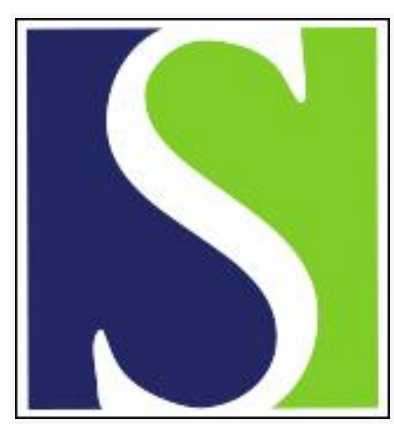

Scand J Work Environ Health 2003;29(3):216-219

https://doi.org/10.5271/sjweh.724

Issue date: Jun 2003

Dependence of palmar sweating response and central nervous system activity on the frequency of whole-body vibration by Ando $H$, Noguchi $R$

Affiliation: Department of Environmental Medicine, Kurume University School of Medicine, 67, Asahi-Machi, Kurume, 839-0011, Japan. hando@med.kurume-u.ac.jp

Refers to the following text of the Journal: 2002;28(5):324-327

Key terms: acute vibration stress; central nervous system activity; palmar sweating response; sympathetic nervous system; vibration frequency; whole-body vibration

This article in PubMed: www.ncbi.nlm.nih.gov/pubmed/12828391

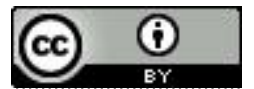




\title{
Dependence of palmar sweating response and central nervous system activity on the frequency of whole-body vibration
}

\author{
by Hideo Ando, MD, ${ }^{1,2}$ Ryo Noguchi, $M D^{1}$
}

\begin{abstract}
Ando $\mathrm{H}$, Noguchi $\mathrm{R}$. Dependence of palmar sweating response and central nervous system activity on the frequency of whole-body vibration. Scand J Work Environ Health 2003;29(3):216-219.

Objectives This study was carried out to determine the effects of the frequency of whole-body vibration on palmar sweating response and the activity of the central sympathetic nervous system.

Methods Palmar sweating volume was measured on the right palm of six healthy men before and during 3 minutes of exposure to sinusoidal whole-body vibration at three different frequencies $(16,31.5$, and $63 \mathrm{~Hz})$. The whole-body vibration had a frequency-weighted, root mean square $(\mathrm{rms})$ acceleration magnitude of $2.0 \mathrm{~m} / \mathrm{s}^{2}$. As the index of the activated central sympathetic nervous system, saliva level of 3-methoxy-4-hydroxyphenylglycol (MHPG) was analyzed before and immediately after each vibration exposure.

Results Each vibration frequency induced a palmar sweating response, that of $31.5 \mathrm{~Hz}$ being the largest. However, no significant difference was found between the three vibration conditions. Saliva MHPG increased in all the vibration exposures, and the largest change was observed at $31.5 \mathrm{~Hz}$, the difference being significant. Conclusions Acute exposure to whole-body vibration induced a palmar sweating response and activated the central sympathetic nervous system. The effects on the central nervous system were found to be dependent on the frequency of the vibration.
\end{abstract}

Key terms acute vibration stress, sympathetic nervous system, vibration frequency.

Exposure to whole-body vibration often occurs in daily life, during work, travel, leisure time and so forth. Whole-body vibration is known to induce several physiological changes, for example, neuromuscular, cardiovascular, and central nervous changes (1). With respect to the central nervous system, an experimental study using animals has shown activation of the sympathetic nervous system during exposure to whole-body vibration (2).

On the other hand, palmar sweating is categorized as mental sweating and occurs during mental, emotion$\mathrm{al}$, or noxious stress (3). In earlier experimental studies, we observed a marked palmar sweating response during such forms of physical stress as exposure to cold ambient temperatures and hand-arm vibration $(4,5)$. Exposure to noise was also observed to induce a palmar sweating response (6).

Clinically, sweating during exposure to whole-body vibration in frequencies ranging from 0.1 to $1 \mathrm{~Hz}$ is known as motion sickness (1). To date, however, few studies have concerned the palmar sweating response during exposure to whole-body vibration in the frequencies caused by occupational vehicles. The aim of our present study was to elucidate the effects of whole-body vibration on palmar sweating response and the central sympathetic nervous system. In addition, we studied the dependency of the effects on vibration frequency.

\section{Subjects and methods}

\section{Subjects}

Six healthy male volunteers with a mean age of 21.3 (SD 2.3) years participated in the study. None of them had previously experienced any occupational exposure to whole-body vibration. One of them was a smoker and

1 Department of Environmental Medicine, Kurume University School of Medicine, Kurume, Japan.

2 Department of Physics, Finnish Institute of Occupational Health, Helsinki, Finland.

Reprint requests to: Dr Hideo Ando, Department of Environmental Medicine, Kurume University School of Medicine, 67, Asahi-machi, Kurume, 830-0011, JAPAN. [E-mail: hando@med.kurume-u.ac.jp] 
was requested to refrain from smoking for at least 2 hours prior to the experiment. Through the series of experiments, all the subjects wore a vest, underpants, a shirt, trousers, and a pair of socks, being estimated to have a clo (resistance of clothing against dry heat loss) value of 0.7 to 0.8 . Written, informed consent was obtained from all of the subjects before they started the experiment.

\section{Measurements}

Palmar sweating was measured by the ventilated capsule method (Hidrograph, AMU-100, Kands, Japan). A capsule $1 \mathrm{~cm}^{2}$ in size was mounted on the right palm of the subject. Dry nitrogen gas was pumped into the capsule at a rate of $0.3 \mathrm{l} / \mathrm{minute}$ on one side, and it exited from the other side after being moistened by the sweat. The sweating volume was automatically estimated from the change of humidity inside the capsule.

As an index of the activated central sympathetic nervous reaction, the saliva level of 3-methoxy-4-hydroxyphenylglycol (MHPG) was assessed before and immediately after the vibration exposure. Samples $(0.5$ $\mathrm{ml}$ ) of saliva were collected from each subject, and saliva MHPG was measured by gas chromatography-mass spectrometry (Hitachi-M80B, Hitachi, Japan) using a deuterium-labeled internal standard (D3-MHPG, from MSD Isotopes, Montreal, Canada) (7).

\section{Vibration exposure}

The subjects were requested to sit on a flat seat without a backrest. Sinusoidal vibration was produced in the vertical direction by an electrodynamic vibrator (Akashi ASE-385, Yokohama, Japan). The vibration frequencies applied to the subjects included $108 \mathrm{~dB}$ at $16 \mathrm{~Hz}, 114$ $\mathrm{dB}$ at $31.5 \mathrm{~Hz}$, and $121 \mathrm{~dB}$ at $63 \mathrm{~Hz}$. The vibration had a frequency-weighted, root-mean-square (rms) acceleration magnitude of $2.0 \mathrm{~m} / \mathrm{s}^{2}$, in accordance with ISO 2631 (8), and produced noise levels of $65.4 \mathrm{~dB}(\mathrm{~A})$ at 16 $\mathrm{Hz}, 66.2 \mathrm{~dB}(\mathrm{~A})$ at $31.5 \mathrm{~Hz}$, and $66.7 \mathrm{~dB}(\mathrm{~A})$ at $63 \mathrm{~Hz}$.

\section{Experimental procedure}

A series of experiments was performed in January and February in an experimental room with an ambient temperature of $22-24^{\circ} \mathrm{C}$ and a relative humidity of $60 \%$. In order to exclude unexpected reactions to vibration, each subject underwent exposure to all the vibration frequencies several times before the experiment was started. At the same time, the subject practiced sitting on the seat in a straight upright position.

After resting in a waiting room for 20 minutes, each subject entered the laboratory. A saliva sample was taken for the measurement of MHPG after a period of acclimatization of 30 minutes, followed by the commencement of continuous recordings of palmar sweating. After the stability of the palmar sweating was confirmed, the subject was exposed for 3 minutes to wholebody vibration while sitting on a vibration platform with his back erect. The subject was not allowed to change his erect position during the experiment. Immediately after the vibration exposure, another saliva sample was obtained. One vibration frequency was applied per day to each subject in a randomized order.

\section{Statistical methods}

Both the volume of palmar sweating and the concentration of saliva MHPG were analyzed quantitatively before and during the three vibration exposures. A repeated-measures analysis of variance (ANOVA) was used to evaluate the differences in the palmar sweating volume and saliva MHPG concentration across the three vibration conditions. When it indicated a significant difference among the responses, a multiple comparison test (Bonferroni test) was used to compare the different conditions. A P-value of 0.05 was set as the limit of statistical significance.

\section{Results}

Figure 1 presents the mean values of the palmar sweating throughout the three vibration conditions. The palmar sweating volume before the exposure did not differ significantly between the three conditions. Acute exposure to any whole-body vibration caused an increase in the palmar sweating response $(\mathrm{F}=9.79, \mathrm{P}=0.01)$.

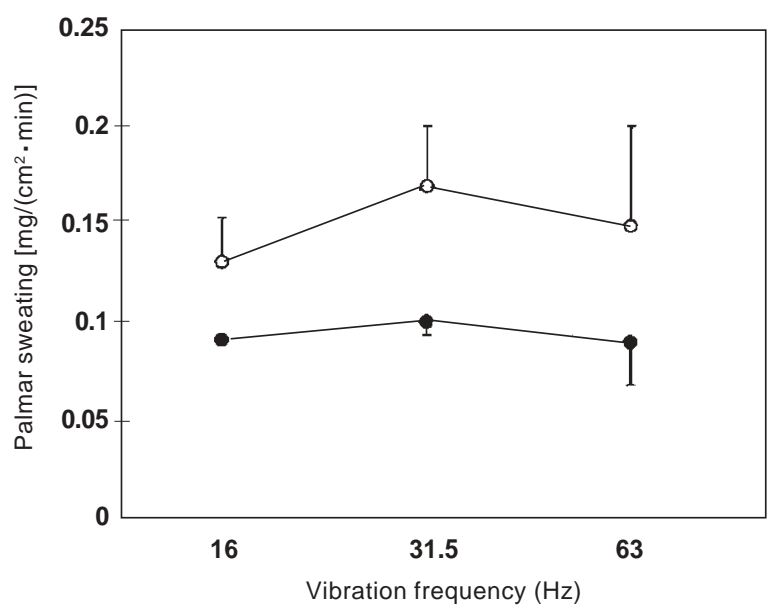

Figure 1. Palmar sweating volumes before and during vibration exposureat threefrequencies. Thevalues represent themeans and standard errors of the means. The closed and open circles show the mean values before and during vibration exposure, respectively. 


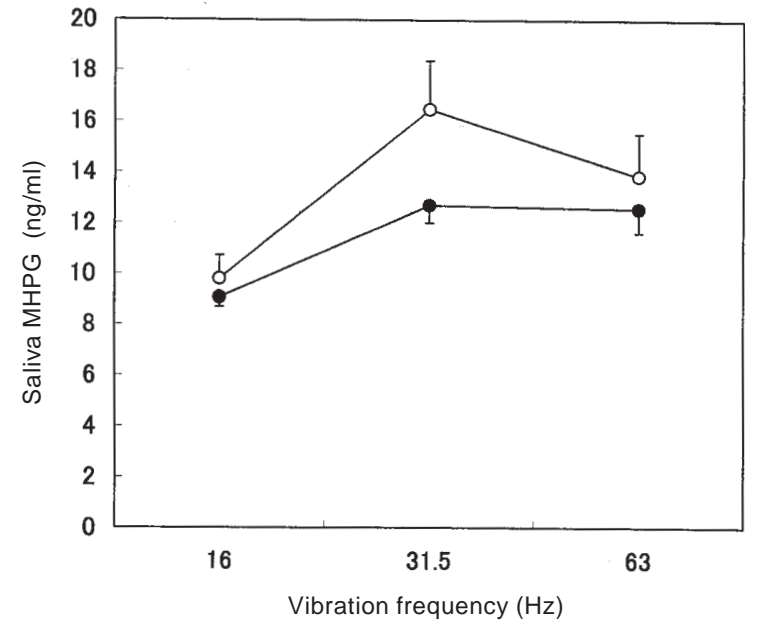

Figure 2. Saliva 3-methoxy-4-hydroxyphenylglycol (MHPG) concentrations before and immediately after three vibration exposures. The values represent the means and standard errors of the means. The closed and open circles show the mean values before and after the vibration exposure, respectively.

Although the repeated-measures ANOVA did not indicate a significant difference between the three vibration conditions $(\mathrm{P}=0.74)$, the largest palmar sweating volume was measured for exposure to vibration at $31.5 \mathrm{~Hz}$, with a mean value of $0.17 \mathrm{mg} /\left(\mathrm{cm}^{2} \cdot \mathrm{min}\right)$, followed by $63 \mathrm{~Hz}$ with $0.15 \mathrm{mg} /\left(\mathrm{cm}^{2} \cdot \mathrm{min}\right)$, and $16 \mathrm{~Hz}$ with $0.13 \mathrm{mg} /$ $\left(\mathrm{cm}^{2} \cdot \min \right)$.

Figure 2 indicates the saliva MHPG concentrations before and immediately after the vibration exposure. That induced by $31.5-\mathrm{Hz}$ vibration was the largest, with a mean of $16.47 \mathrm{ng} / \mathrm{ml}$, followed by $63 \mathrm{~Hz}$ with a mean of $13.85 \mathrm{ng} / \mathrm{ml}$ and $16 \mathrm{~Hz}$ with a mean of $9.79 \mathrm{ng} / \mathrm{ml}$. Acute exposure to all the whole-body vibration frequencies caused an increase in the saliva MHPG concentration $(\mathrm{F}=7.15, \mathrm{P}=0.02)$. The repeated-measures ANOVA indicated a significant difference in the saliva MHPG concentration between the three vibration frequencies ( $\mathrm{F}=6.55, \mathrm{P}=0.01)$. The Bonferroni test showed that the change in the saliva MHPG concentration at $31.5 \mathrm{~Hz}$ was significantly greater than that at $16 \mathrm{~Hz}(\mathrm{P}<0.01)$.

\section{Discussion}

The palmar sweating response to hand-arm vibration has been investigated in some studies $(5,6)$, but, as far as we know, neither laboratory nor epidemiologic studies have been carried out with respect to the effect of wholebody vibration. In our present study, we evaluated palmar sweating and saliva MHPG at three different wholebody vibration frequencies. Acute exposure to wholebody vibration was found to cause an increase in both palmar sweating volume and saliva MHPG concentration.
MHPG is known as a major metabolite of norepinephrine in the human brain (9). Physical stress, such as electrical stimulation applied to the forearm, has been found to increase urinary MHPG (10). According to Drebing et al (11), the saliva level of MHPG correlates significantly with the plasma level of MHPG, and it can be a useful and noninvasive tool for detecting changes in central norepinephrine metabolism. In addition, recent research has shown a high correlation between the MHPG in saliva and that in cerebrospinal fluid (12). We used the saliva MHPG concentration as an index of an activated central sympathetic nervous system. Consequently, the increase in saliva MHPG observed during exposure to whole-body vibration in our study suggests that whole-body vibration stimulates the central nervous system, including the hypothalamus. In addition, we observed that the change in the saliva MHPG concentration at $31.5 \mathrm{~Hz}$ was the largest of the three vibration conditions used; this finding suggests that the activation of the central nervous system is dependent on the frequency of vibration. In general, vibration between 20 and $30 \mathrm{~Hz}$ is considered to set up the strongest resonance between the head and shoulders (13). An augmented vibration magnitude at the cranial level at 31.5 $\mathrm{Hz}$ may activate the central nervous system more intensely than other vibration frequencies with the same frequency-weighted acceleration magnitude.

Palmar sweating is categorized as "mental sweating", and it occurs during mental, emotional, or noxious stress. Two mechanisms have been suggested to induce a palmar sweating response as a result of such stress. One is associated with the central sympathetic nervous system (14) and the other with the sympathetic reflex (15). The changes in the saliva MHPG concentration observed in our study indicate that the palmar sweating response to whole-body vibration is probably due to the activation of the central sympathetic nervous system. Although the repeated-measures ANOVA did not indicate a significant difference between the three vibration conditions, the palmar sweating response at $31.5 \mathrm{~Hz}$ was the largest, possibly reflecting the strongest activation of the central nervous system. However, another mechanism for the palmar sweating response cannot be excluded. An experimental study using animals has shown that stimulation of the vestibular nerve induces a galvanic skin reflex, namely, sweating, in the forepaws of cats through a vestibulo-sympathetic reflex (16). Our study suggested that a vibration frequency of $31.5 \mathrm{~Hz}$ induces the greatest reaction of the vestibular apparatus, which detects the position and motion of the head and results in a greater palmar sweating response through the vestibulo-sympathetic reflex.

Noise levels as high as $105 \mathrm{~dB}(\mathrm{~A})$ have been shown to increase palmar sweating (6). In our study, the 
environmental noise levels were between 65.4 and 66.7 $\mathrm{dB}(\mathrm{A})$. Our previous study (17), in which hand-arm vibration produced noise levels between 63.5 and 65.7 $\mathrm{dB}(\mathrm{A})$, indicated that noise levels in this range do not induce significant palmar sweating responses. In addition, Mocci et al (18) observed that an average level of sound energy as high as $98 \mathrm{~dB}(\mathrm{~A})$ produced no significant increase in urinary catecholamine (18). These findings suggest that the noise levels produced in our present study could neither activate the central nervous system nor induce a palmar sweating response.

There are some potential limitations to our study. First, the vibration exposure levels of off-road construction vehicles such as bulldozers and excavators measure above $2.0 \mathrm{~m} / \mathrm{s}^{2} \mathrm{rms}$, while those of on-road vehicles such as trucks and vans are less than $2.0 \mathrm{~m} / \mathrm{s}^{2} \mathrm{rms}$ (19). Moreover, the frequencies used in the study were not the most representative of those produced by occupational vehicles. More research is needed on the effects of whole-body vibration on palmar sweating response at lower frequencies with weaker magnitudes. Second, the sample size of our study did not seem to be large enough to show a significant difference in the palmar sweating response between the three vibration conditions. Still, the palmar sweating response suggested a dependency on vibration frequency and, therefore, reflected a frequency-dependent activation of the central nervous system. Third, it was beyond our study to show any neurological evidence for the degree to which the sympathetic reflex was responsible for the palmar sweating response to whole-body vibration.

In conclusion, exposure to whole-body vibration induced a palmar sweating response and activated the central nervous system. The activation of the central nervous system indicated a dependency on vibration frequency.

\section{Acknowledgments}

We would like to thank Emeritus Professor T Matoba, Kurume University School of Medicine, and Professor T Ishitake, Department of Environmental Medicine, Kurume University School of Medicine, for their continuous support during the study. We also gratefully acknowledge the assistance of Professor S Yamada, Saga Medical College, and all the staff of the Institute of Brain Diseases, Kurume University School of Medicine, who instructed us in the measurement of saliva MHPG.

\section{References}

1. Griffin MJ. Handbook of human vibration. London: Academic Press; 1990.
2. Okada A, Ariizumi M, Okamoto G. Changes in cerebral norepinephrine induced by vibration or noise stress. Eur J Appl Physiol 1983;52:94-7.

3. Kuno Y. Human perspiration. Springfield (IL): Thomas; 1956. Cited in Ogawa T. Thermal influence on palmar sweating and mental influence on generalized sweating in man. Jpn J Physiol 1975;52:525-36.

4. Ando H, Noguchi R, Ishitake T, Matoba T. Effect of cold ambient temperature on palmar sweating response to vibration stress. Eur J Appl Physiol 2002;87:315-7.

5. Ando H, Ishitake T, Miyazaki Y, Kano M, Tsutsumi A, Matoba $\mathrm{T}$. The mechanism of a human reaction to vibration stress by palmar sweating in relation to autonomic nerve tone. Int Arch Occup Environ Health 2000;73:41-6.

6. Sakakibara H, Kondo T, Koike Y, Miyao M, Furuta M, Yamada $\mathrm{S}$, et al. Combined effects of vibration and noise on palmar sweating. Eur J Appl Physiol 1989;59:195-8.

7. Maas JW, Hattox SE, Landis DH, Roth RH. The determination of a brain arteriovenous difference for 3-methoxy-4-hydroxyphenylethyleneglycol (MHPG). Brain Res 1976;118: 167-73.

8. International Organization for Standardization (ISO). Evaluation of human exposure to whole-body vibration-part 1: general reguirements. Geneva: ISO; 1997. ISO 2631-1.

9. Goodman Gilman A, Rall T, Nies A, Taylor P. Goodman and Gilman's: the pharmacological basis of therapeutics. 8th ed. New York (NY): Macmillan; 1990.

10. Buchsbaum MS, Muscettola G, Goodwin FK. Urinary MHPG, stress response, personality factors and somatosensory evoked potentials in normal subjects and patients with major affective disorders. Neuropsychobiology 1981;7:212-24.

11. Drebing CJ, Freedman R, Waldo M, Gerhardt GA. Unconjugated methoxylated catecholamine metabolites in human saliva. Quantitation methodology and comparison with plasma levels. Biomed Chromatogr 1989;3:217-20.

12. Reuster T, Rilke O, Oehler J. High correlation between salivary MHPG and CSF MHPG. Psychopharmacology 2002; $162: 415-8$

13. Wasserman DE. Occupational exposure to vibration. In: Rom WN, editor. Environmental and occupational medicine. 3rd ed. Philadelphia (PA): Lippincott-Raven Publication; 1998.

14. Matoba T, Chiba M, Sakurai T. Body reactions during chain saw work. Br J Ind Med 1985;42:667-71.

15. Sato A, Schmidt RF. Somatosympathetic reflexes: afferent fibers, central pathways, discharge characteristics. Physiol Rev 1973;53:916-47.

16. Ishikawa T, Miyazawa T. Sympathetic responses evoked by vestibular stimulation and their interactions with somato-sympathetic reflexes. J Auton Nerv Syst 1980;1:243-54.

17. Ando H, Noguchi R, Ishitake T. Frequency dependence of hand-arm vibration on palmar sweating response. Scand $\mathrm{J}$ Work Environ Health 2002;28:324-27.

18. Mocci F, Canalis P, Tomasi PA, Casu F, Pettinato S. The effect of noise on serum and urinary magnesium and catecholamines in humans. Occup Med 2001;51:56-61.

19. Schneider S, Johanning E, Bélard JL, Engholm G. Noise, vibration, and heat and cold. Occup Med 1995;10:363-83.

Received for publication: 4 September 2002 